Check for updates

New York

Cite this as: $B M J 2021 ; 375: n 3134$ http://dx.doi.org/10.1136/bmj.n3134 Published: 22 December 2021

\section{Covid 19: Biden promises more tests and help for hospitals, but no lockdowns, as cases soar}

\author{
Janice Hopkins Tanne
}

President Joe Biden promised Americans half a billion home tests for covid-19 and medical help from the US military at hard pressed hospitals, but no lockdowns, as the nation faces a surge of cases from the omicron variant. ${ }^{1}$

Speaking at the White House on 21 December Biden offered reassurance but warned those who are unvaccinated, "We should all be concerned about omicron but not panicked. If you're fully vaccinated, and especially if you got your booster shot, you are highly protected. If you're unvaccinated, you're at higher risk of getting severely ill from covid-19, getting hospitalised, and even dying." He called vaccination "a patriotic duty."

Although cases are expected to surge in January, Biden said that businesses and schools could stay open following a "vaccine or test" rule for workers and mask wearing. Vaccinations are free for those aged 5 and over.

There are about 143 ooo new cases every day, about 69 oo new hospital admissions, and about 1300 new deaths compared with two weeks ago. More than 51 million Americans have had covid-19 and more than 800 ooo have died. ${ }^{2}$ Of the 400 ooo who died this year, almost all were unvaccinated, Biden said. He criticised the "dangerous misinformation" on television and social media.

A Centers for Disease Control and Prevention (CDC) report suggested a January surge of covid-19 cases that "could exceed previous peaks."3 North eastern states have seen rapid increases of cases in the past two weeks-up 81\% in New York, 75\% in New Jersey, and $51 \%$ in Rhode Island. ${ }^{3}$

Cases caused by the omicron variant have gone from $3 \%$ to $73 \%$ in just a few weeks, said Rochelle Walensky, director of the CDC, speaking on the PBS Newshour on 21 December. Most new cases are now caused by the variant. 4

About 40 million Americans are still unvaccinated. Around 241 million have received two shots of the Pfizer BioNTech or Moderna vaccines or two shots and a booster, according to the CDC. ${ }^{5}$ Walensky did not respond to questions about a possible fourth shot, which is already being used in Israel.

Biden said that the government had opened 10000 new vaccination sites in addition to the 80000 already in place. More will open in January. Starting immediately, hundreds more vaccinators will be deployed to these sites. The Federal Emergency Management Agency (FEMA) is setting up new vaccination sites nationwide to provide booster shots, especially in areas of high demand.
In New York City, where daily cases surged from a seven day average of 1900 to nearly 9300, Mayor Bill de Blasio offered a $\$ 100$ incentive to people who get a booster between now and the end of the year at sites run by the city or a community organisation. Many sites are in underserved areas. ${ }^{6}$

\section{More tests and help for hospitals}

Testing, Biden said, was important in order to know who was infected and to stop the spread of the virus. There are some 20 ooo free testing sites, but more will be opened in hard hit areas. Biden said people could easily find a test site by typing "covid test near me" into a search engine.

Half a billion home tests kits will be sent free to people who order them online, starting next month.

Because hospitals will be stressed when the unvaccinated become ill, Biden said that the administration had stockpiled gowns, gloves, masks, and ventilators to be sent to any state that needs more. Some 1000 military doctors, nurses, and medics will be sent to help hospitals in the worst affected areas. Teams have already been sent to Indiana and Wisconsin.

In addition, teams will be sent to construct emergency capacity facilities near hospitals- "in parking garages and nearby buildings to be ready if needed," Biden said. FEMA will also send hundreds of ambulances and emergency medical service crews "so that if one hospital fills up, we can transport patients to beds elsewhere." Dozens of ambulances will be sent to New York and Maine this week "because covid is spreading very rapidly” in those areas, he said.

Remarks by President Biden on the fight against covid-19. 21 December 2021. www. whitehouse.gov/briefing-room/statements-releases/2021/12/21/remarks-by-president-biden-on-the-fight-against-covid-19.

2 New York Times coronavirus tracker. New York Times. 21 December 2021 www.nytimes.com/interactive/2021/us/covid-cases.html.

3 Centers for Disease Control and Prevention. Potential rapid increase of omicron variant infections in the United States. 20 December 2021. www.cdc.gov/coronavirus/2019-ncov/science/forecasting/mathematicalmodeling-outbreak.html\#print.

4 PBS Newshour. 21 December 2021. www.pbs.org/newshour/show/drwalensky-on-the-omicron-variant-testing-vaccines-and-mask-rules. Centers for Disease Control and Prevention. Covid data tracker. https://covid.cdc.gov/covid-data-tracker/\#vaccinations_vacc-total-adminrate-total.

6 Cerullo M. NYC offering $\$ 100$ to residents who get covid-19 booster. https://covid.cdc.gov/covid-data-tracker/\#vaccinations_vacc-total-adminrate-total. terms and conditions for the duration of the covid-19 pandemic or until otherwise determined by BMJ. You may use, download and print the article for any lawful, non-commercial purpose (including text and data mining) provided that all copyright notices and trade marks are retained.
This article is made freely available for use in accordance with BMJ's website 